\title{
Educate for dejudicialization: the inclusion of cooperative practices in legal teaching
}

\section{Educar para a desjudicialização: a inclusão de práticas cooperativas no ensino jurídico}

\section{Educar para la desjudicialización: la inclusión de prácticas cooperativas en la enseñanza jurídica}

\author{
Fabiana Marion Spengler ${ }^{1}$ (D), Maini Dornelles ${ }^{1}$ (D) \\ ${ }^{1}$ Universidade de Santa Cruz do Sul, Santa Cruz do Sul, Rio Grande do Sul, Brasil. \\ Autor correspondente: \\ Maini Dornelles \\ Email: maini_md@hotmail.com \\ Como citar: Spengler, F. M., \& Dornelles, M. (2021). Educate for dejudicialization: the inclusion of cooperative \\ practices in legal teaching. Revista Tempos e Espaços em Educação, 14(33), e14288. \\ http://dx.doi.org/10.20952/revtee.v14i33.14288
}

\begin{abstract}
The first Law course was created in 1827 and since then professionals have been trained in litigation. With the enactment of the Federal Constitution of 1988, access to justice became a basic right and so lawyers started to represent their clients in the Jurisdiction, however, this should be the last rattio, after extrajudicial attempts to resolve conflicts. That said, the question is: if inserted in legal education, can cooperative practices educate future jurists for de-judicialization? To answer the proposed problem, the method of deductive approach will be used, starting from a general analysis, studying the creation and evolution of law courses in Brazil, to reach the specifics that it is the need to include cooperative practices in the curriculum of the course. The method of procedure will be monographic. The objective of this research is to investigate the need to include cooperative practices in legal education, aiming at the humanistic training of future jurists with an emphasis on de-judicialization of access to justice.
\end{abstract}

Keywords: Access to justice. Cooperative practices. Desjudicialization. Legal training.

\section{RESUMO}

O primeiro curso de Direito foi criado no ano de 1827 e desde então os profissionais têm sua formação voltada para o litígio. Com a promulgação da Constituição Federal de 1988 o acesso à justiça se tornou um direito básico e assim os advogados passaram a representar seus clientes junto à Jurisdição, toda via, está deveria ser a última rattio, após tentativas extrajudiciais de solucionar conflitos. Posto isto, questiona-se: se inseridas no ensino jurídico, as práticas cooperativas podem educar os futuros juristas para a desjudicialização? Para responder a problemática proposta será 
utilizado o método de abordagem dedutivo, partindo de uma análise geral, estudando a criação e evolução dos cursos de direito no Brasil, para chegar a especifica que é a necessidade de incluir práticas cooperativas nas matrizes curriculares do curso. O método de procedimento será o monográfico. Objetiva-se com a presente pesquisa investigar a necessidade de inclusão de práticas cooperativas no ensino jurídico, visando a formação humanística dos futuros juristas com ênfase na desjudicialização do acesso à justiça.

Palavras-chave: Acesso à justiça. Desjudicialização. Formação jurídica. Práticas cooperativas.

\section{RESUMEN}

El primer curso de Derecho se creó en 1827 y desde entonces se han formado profesionales en litigio. Con la promulgación de la Constitución Federal de 1988, el acceso a la justicia se convirtió en un derecho básico y así los abogados pasaron a representar a sus clientes en la Jurisdicción, sin embargo, esta debería ser la última proporción, luego de intentos extrajudiciales de resolución de conflictos. Dicho esto, la pregunta es: si se insertan en la educación jurídica, ¿pueden las prácticas cooperativas educar a los futuros juristas para la desjudicialización? Para responder al problema propuesto, se utilizará el método de enfoque deductivo, a partir de un análisis general, estudiando la creación y evolución de los cursos de derecho en Brasil, para precisar que existe la necesidad de incluir prácticas cooperativas en las matrices curriculares del curso. El método de procedimiento será monográfico. El objetivo de esta investigación es investigar la necesidad de incluir prácticas cooperativas en la educación jurídica, con el objetivo de la formación humanística de los futuros juristas con énfasis en la desjudicialización del acceso a la justicia.

Palabras clave: Acceso a la justicia. Desjudicialización. Entrenamiento legal. Prácticas cooperativas.

\section{INTRODUÇÃO}

No Brasil a formação de futuros juristas passou por numerosas mudanças, sendo que no primeiro curso de Direito instituído em 1827 os acadêmicos eram educados para assumir cargos políticos junto aos governantes estatais e nos dias atuais, são formados para o litígio. Entretanto, a sociedade passa por mudanças, sendo necessário adotar um novo viés formativo para os operadores do direito.

Com o intuito de estudar mudanças possíveis para as matrizes curriculares dos cursos de direito no país, propõe-se a seguinte problemática de pesquisa: se inseridas no ensino jurídico, as práticas cooperativas podem educar os futuros juristas para a desjudicialização? Para responder a problemática proposta será utilizado o método de abordagem dedutivo, partindo de uma análise geral, estudando a criação e evolução dos cursos de direito no Brasil, para chegar a especifica que é a necessidade de incluir práticas cooperativas nas matrizes curriculares do curso. $O$ método de procedimento será o monográfico.

Para responder o questionamento será feito uma análise acerca da criação e da evolução dos cursos de direito no Brasil, perpassando por um ensino elitista que previa a formação de governantes estatais até os dias atuais, onde busca-se uma formação humanizada e cooperativa dos juristas. Seguindo este fio condutor, será feita uma abordagem dos procedimentos cooperativos que visam a desjudicialização do acesso à justiça, dando ênfase as práticas de mediação e advocacia colaborativa, que põe os conflitantes do centro da resolução da demanda conflitiva.

Por fim, será feito um estudo acerca da importância de incluir práticas cooperativas no ensino jurídico, formando profissionais menos beligerantes e mais humanos quando incumbidos da responsabilidade de auxiliar um cliente na resolução de um conflito.

Conclui-se que é preciso percorrer um longo caminho para que seja possível romper com o paradigma de uma formação para litigio, mas acredita-se que o primeiro passo é incluir práticas cooperativas nas matrizes curriculares dos cursos de direito, objetivando uma formação mais humana, o que a longo prazo trará resultados positivos para toda sociedade, que não precisaram 
levar suas demandas ao Judiciário para que um terceiro lhes diga quem é detentor de maior direito ou razão.

\section{CRIAÇÃO E DESENVOLVIMENTO DOS CURSOS DE DIREITO NO BRASIL}

O ensino jurídico teve início no Brasil no século XIX quando sancionada a carta de Lei de 11 de agosto de 1827, que instituía cursos de Direito nos estados de São Paulo e Olinda (MARTINEZ, 2004). Inicialmente as faculdades jurídicas, tinham como objetivo formar cidadãos da elite econômica, que tivessem pensamento nacionalista para governança e uma política administrativa do País (Brigagão, 2020).

Os projetos educacionais de diversos cursos superiores no País estavam a serviço das elites, que detinham o poder político e econômico, gerando um ciclo de dependência. Ainda neste período os estudantes brasileiros puderam acompanhar as novidades da época, consideradas liberais, que vinham da Universidade de Coimbra-Portugal, influenciados especialmente pela Reforma Pombalina ${ }^{1}$ (Martinez, 2004).

A tendência de liberalidade se dava, quando a Lei que criou os dois cursos de direito no Brasil, trazia uma estrutura curricular una ${ }^{2}$. Um novo discurso jurisdicional surge com o fim do absolutismo, e requer com que novas bases teóricas sejam trabalhadas nas faculdades, estas embasadas em uma sociedade moderna que estava em construção (Martinez, 2004).

Em 1880 um novo currículo foi estipulado para os Cursos de Direito, incluindo disciplinas como filosofia, história e direito comparado. Outra mudança também foi o público alvo que, apesar da maioria dos acadêmicos comporem a classe elitista, outros cidadãos com aspiração sociais também ingressavam no curso de direito, talhando uma nova era para o ensino superior no Brasil (Brigagão, 2020).

Em um curto período de tempo foram criadas mais de 80 faculdades de Direito, sendo que o modelo de formação foi chamado "fordista" remontado a "fábrica de bacharéis", tendo em vista que a atuação dos futuros juristas, teriam como pano de fundo uma reprodução contínua do modelo liberal (Martinez, 2004, p. 06).

Na década de 1930 período reconhecido como "Era Getúlio", foi revogada a Constituição vigente e, o então presidente Getúlio Vargas passou a legislar por meio de decretos presidenciais. Neste interregno de tempo, foi instituído o Ministério da Educação e aprovado o parecer no 2015 que instituía uma nova matriz curricular que dispunha os conteúdos a serem estudados no ensino jurídico (Bissoli Filho, 2012).

Entre 1946 e 1964 aconteceu a reforma do currículo mínimo, por meio da Lei no 4.042, que estabeleceu diretrizes e bases da educação nacional e definiu que ficaria sob responsabilidade do Conselho Federal de Educação em conjunto com as instituições de ensino a estruturação dos currículos formadores.

No período em que perdurou a ditadura militar no Brasil, os cursos superiores passaram por grande expansão, especialmente em faculdades privadas. Acredita-se que pelo fato de haver vigilância severa nas universidades públicas, com o intuito de conter movimentos estudantis (Brigagão, 2020). Com o fim da ditadura militar para o Estado Democrático de Direito, houve vasta ampliação dos direitos sociais, além do aumento de possibilidades no mercado de trabalho, sendo

\footnotetext{
${ }^{1}$ Proposta de reforma educacional realizada por Marquês de Pombal. Nessa análise, apontam para as consequências da proposta pombalina para a educação brasileira e portuguesa, em cujo contexto social estavam presentes ideias absolutistas, de um lado, e ideias iluministas inspiradoras de Pombal, de outro lado (Maciel; Shigunov Neto, 2006).

2 1ㅇ Ano - 1a Cadeira. Direito Natural, Público, Análise da Constituição do Império, Direito das Gentes e Diplomacia. 2으 Ano - 1a Cadeira. Continuação das matérias do ano antecedente. 2a Cadeira. Direito Público Eclesiástico. 3으 Ano - lạ Cadeira. Direito Pátrio Civil. 2ª Cadeira. Direito Pátrio Criminal, com a teoria do processo criminal. 4으 Ano - 1a Cadeira. Continuação do Direito Pátrio Civil. 2a Cadeira. Direito Mercantil e Marítimo. 5o- Ano - 1a Cadeira. Economia Política. 2a Cadeira. Teoria e prática do processo adotado pelas leis do Império (Martinez, 2004).
} 
necessárias mudanças na formação dos profissionais para manuseio de práticas forenses foram necessárias (Bissoli Filho, 2020).

A Lei no $4.215^{3}$ criada promulgada em 1963 criou o Estatuto da Ordem dos Advogados do Brasil, que instituiu o estágio obrigatório e o exame de ordem, que tinha como intuito frear a colocação de profissionais sem qualificação no mercado de trabalho, pois haviam muitos cursos de direito, com baixo padrão de ensino no país (Bissoli Filho, 2012).

Quando promulgada, a Constituição Federal de 1988 estabeleceu no artigo 205 que "a educação é direito de todos e dever do Estado e da família" [... $]^{4}$. Almejava-se neste período tecer mudanças, especialmente no ensino fundamental, fortalecendo a necessidade de educação de qualidade, que formasse profissionais para que atuassem no mercado de trabalho.

A Carta Magna trouxe esperança para os brasileiros e a partir daquele momento, numerosos direitos e garantias ${ }^{5}$ ecoaram pelo país, não sendo aceitos mais profissionais mecânicos, sendo necessário mínima formação técnica para cumprir com o exposto na legislação.

A matriz curricular dos cursos de direito passou por diversas mudanças ${ }^{6}$, sendo por meio da portaria no 1.886 de 30 de dezembro de 1994, que a partir do ano de 1996, todos os acadêmicos de direito deveriam apresentar trabalho de conclusão de curso e realizar estágio obrigatório, para torna-se advogado (Bissoli Filho, 2012).

Objetivou-se fazer uma breve análise histórica a respeito da implementação dos cursos de direito no Brasil, sem o intuito de esgotar o tema. Deste modo, dar-se-á um salto temporal para estudar a Resolução ${ }^{7}$ no 05 de 2018, do Ministério da Educação. 0 tema será aprofundado no terceiro item do trabalho, perfazendo uma análise que assegura uma formação humanística e formas consensuais de tratamento de conflito, objetivando formar profissionais com capacidade autônoma e dinâmica.

O desenvolvimento e aprimorando do ensino jurídico resta claro, outrossim, acredita-se haver um longo caminho a ser trilhado para formar profissionais menos mecânicos e litigantes, e formar juristas mais humanos. Serão estudadas práticas cooperativas e a importância dos procedimentos extrajudiciais para fomentar a pacificação social.

\section{A IMPORTÂNCIA DA DESJUDICIALIZAÇÃO DE CONFLITOS: MEDIAÇÃO E ADVOCACIA COLABORATIVA EM FOCO}

Os procedimentos cooperativos/colaborativos conquistam espaço no cenário Jurídicos brasileiro especialmente pelo exaurimento do Poder Judiciário e de morosidade processual, entretanto as práticas expressam muito mais que um mecanismo célere de tratar conflitos, pois colocando os conflitantes no centro do tratamento da contenda fomentam o diálogo e a pacificação social.

Ainda recentes, porém apresentando-se como uma forma efetiva de descentralização do judiciário, os procedimentos desjudicializadores estão sendo cada vez mais reconhecidos pelos operadores do Direito no cenário jurídico brasileiro. A situação permite despir a justiça de simbolismos, status social, dentre outras amarras perpetuadas ao longo dos anos. Os procedimentos extrajudiciais "[...] não excluem ou evitam um sistema judicial caótico, mas põem-

\footnotetext{
${ }^{3}$ Esta Lei perdeu a eficácia quando foi criado o Estatuto da Ordem dos Advogados do Brasil que regulamenta o exercício da profissão. Disponível em: http://www.planalto.gov.br/ccivil 03/leis/l8906.htm

4 "A educação, direito de todos e dever do Estado e da família, será promovida e incentivada com a colaboração da sociedade, visando ao pleno desenvolvimento da pessoa, seu preparo para o exercício da cidadania e sua qualificação para o trabalho" (Brasil, 1988).

${ }^{5}$ A Constituição Federal de 1988 traz inúmeros direitos e garantias que o Estado não consegue prover de forma integral, o que levou a explosão de litígios judiciais, visando a garantia de tais direitos.

${ }^{6}$ Até o ano de 1990, refere-se pelo menos 14 mudanças no ensino jurídico brasileiro (Bissoli Filho, 2012).

${ }^{7}$ Está resolução é sobre as Diretrizes curriculares para os cursos de Direito (Ministério da educação, 2018).
} 
se interativamente ao lado da jurisdição estatal, devendo-se valer do critério de adequação entre a natureza do conflito e o meio de solução que entenda mais apropriado" (Calmon, 2013, p. 46). Na presente pesquisa será dando ênfase ao estudo dos procedimentos de mediação e advocacia colaborativa.

A mediação 8 é uma prática milenar, na qual um terceiro fica responsável por mediar o diálogo entre pessoas envolvidas em um conflito. Há alguns anos, a prática vem ganhando espaço no cenário jurídico visto a necessidade de encontrar respostas para um problema preocupante: a falta de diálogo e os altos índices de litigiosidade.

Segundo Cabral (2017), a mediação é uma prática de resolução conflitiva em que as partes constroem de forma conjunta uma decisão, satisfazendo, dessa forma, todos os envolvidos e fortalecendo as relações sociais com a ação de um terceiro ${ }^{9}$, que realiza intermediações e facilita o diálogo em busca do entendimento.

O modelo de jurisdição tradicional adota a prática adversarial, na qual há um perdedor e um ganhador, já no modelo cooperativo proposto com base nos métodos autocompositivos, o tratamento de conflitos se dá por práticas não adversárias, fundadas no modelo ganha-ganha (Spengler, 2021). Enquanto a mediação é considerada uma forma "ecológica" de resolver conflitos, sejam estes sociais ou jurídicos, é um instrumento que visa a satisfação de ambos os lados, substituindo a aplicação de uma sanção legal (Warat, 2004, p. 05).

O procedimento de mediação faz com que muitos sentimentos venham à tona: raiva, angustias, magoa e até mesmo amor, por este motivo é de extrema relevância que o profissional que vai mediar o debate valide os sentimentos dos envolvidos (Spengler, 2021). Dentre as principais características do procedimento de mediação estão: confidencialidade, economia financeira e de tempo, oralidade, reaproximação das partes, autonomia, equilíbrio das relações (Morais \& Spengler, 2019).

No ano de 2015 foi publicada a Lei n. 13.140 (Brasil), que ganhou espaço no cenário jurídico e passou a ser reconhecida como marco legal da mediação. Já no ano de 2016, a mediação foi regulamentada em âmbito trabalhista por meio da Resolução n. 174/2016 do Conselho Superior da Justiça do Trabalho (Brasil, 2016). É mister lembrar que, já no ano de 2010, a Resolução n. 125 do Conselho Nacional de Justiça -CNJ (Brasil, 2010) disciplinava sobre a Política Judiciária Nacional de tratamento dos conflitos de interesse no âmbito do Poder Judiciário. Todas as legislações citadas apresentam um rol de princípios que norteiam a prática e, apesar de não serem iguais, apresentamse de forma conexa.

A Resolução 125/2010 do CNJ, no anexo III, art. 1ํ, dispõe o Código de Ética de Conciliadores e Mediadores Judiciais, determina os seguintes princípios fundamentais como norteadores da atuação de conciliadores e mediadores judiciais: confidencialidade, decisão informada, competência, imparcialidade, independência e autonomia, respeito à ordem pública e às leis vigentes, empoderamento e validação. O art. 166, caput, do CPC dispõe que: “A conciliação e a mediação são informadas pelos princípios da independência, da imparcialidade, da autonomia da vontade, da confidencialidade, da oralidade, da informalidade e da decisão informada". Além destes, cabe destacar o princípio da cooperação, conforme a redação do art. 60: "Todos os sujeitos do processo devem cooperar entre si para que se obtenha, em tempo razoável, decisão de mérito justa e efetiva". No art. 2으, a Lei da Mediação elenca os seguintes princípios: I)

\footnotetext{
${ }^{8}$ Ressalta-se que, sobre a mediação, pretende-se fazer uma abordagem geral, sem abordar suas diversas formas como: mediação escolar, mediação comunitária, mediação extrajudicial, mediação sanitária e mediação on-line.

9 “O mediador não é um mero assistente passivo, mas sim um moderador de ideias, que mostrará o sentido da realidade necessário para atingir acordos convenientes. Ele se vale de técnicas especiais e com habilidade escuta as partes, as interroga, apaga o problema, cria opções e tem como alvo que as partes cheguem à sua própria solução para o conflito (autocomposição). É fundamental que o mediador não expresse sua opinião sobre o resultado do pleito. Tal atitude consiste na regra de ouro do mediador (mas não a única)" (Calmon, 2013, p. 121).
} 
imparcialidade do mediador; II) isonomia entre as partes; III) oralidade, IV) informalidade; V) autonomia da vontade das partes; VI) busca do consenso; VII) confidencialidade; e VIII) boa-fé. No âmbito trabalhista, a Resolução 174/2016 do CSJT, anexo II, art. 1으, prevê os seguintes princípios fundamentais: decisão informada, competência, imparcialidade, independência e autonomia, respeito à ordem pública e às leis vigentes, empoderamento e validação. Percebese que esta Resolução segue os termos da Resolução 125/2010 do CNJ, contudo não menciona o princípio da confidencialidade. Tal medida pode estar relacionada com o objeto de disputa, mas não se pode olvidar que o procedimento de mediação é construído a partir do diálogo franco entre o mediador e os mediandos. Logo, em um ambiente onde não se consegue assegurar o sigilo das informações, dificilmente se consolidará uma relação de confiança (Schaefer, 2021, p. 47).

O procedimento de mediação regulamentado por meio de lei deu espaço a uma antiga forma de tratamento de conflitos que, apesar de institucionalizada, deve manter sua essência: tornar protagonistas as partes da demanda conflitiva por meio do diálogo respeitoso com o auxílio do mediador, buscando a melhor solução para os envolvidos.

Outro procedimento que é novo e ainda pouco conhecido no Brasil é a advocacia colaborativa ${ }^{10}$ teve início nos Estados Unidos, no ano de 1990, quando Stuart Webb ${ }^{11}$, um advogado de direito de família renomado, passou a sentir que mesmo tendo vitória nos casos que atuava, os resultados no que tange a vida pessoal de seus clientes era sempre prejudicial e decidiu que não trabalharia mais com casos contenciosos (Gomes, 2019). Assim, o advogado reformulou sua forma de atuar optando por defender os reais interesses de seus clientes, dando ênfase na realização de acordos e renunciando ao litigio (Souza \& Santos, 2018).

$\mathrm{O}$ procedimento chegou ao Brasil quando alguns ${ }^{12}$ profissionais foram ao exterior para aprender como realizar o mecanismo. Retornando desta viagem organizaram grupos de estudos para pôr em prática os conhecimentos adquiridos (Pinho \& Alves; 2014).

A advocacia colaborativa é um procedimento extrajudicial, tem como base a autonomia de vontade e liberdade que os envolvidos têm para conduzir interesses patrimoniais e pessoais, com o auxílio de profissionais qualificados, além de advogados podendo ser contadores e psicólogos.

Quando os envolvidos optam pelo procedimento da advocacia colaborativa, os profissionais assinam um acordo de não litigância, ou seja, caso não alcancem o consenso, terão de procurar outros profissionais para lhes auxiliar com o ingresso de uma ação judicial.

A escolha do advogado em regra é um dos primeiros passos quando se está envolto de um conflito, sendo que em suma maioria as pessoas vão contratar os profissionais reconhecidos como "grandes litigantes" ou "bom no tribunal" (Webb \& Uousky, 2017, p. 21), e se, a parte A, já souber o advogado da parte $B$, vai contratar um advogado mais beligerante ainda, afinal é preciso "combater fogo com fogo" (Webb \& Uousky, 2017, p. 21). As partes não pensam neste momento a importância de contratar um profissional que seja um exímio negociador, que poderá lhe trazer inúmeras vantagens na resolução do problema.

O advogado que possui um rol de técnicas de negociação pode se destacar e permitir que as partes explorem diversas opções até que encontrem a melhor para o seu problema, assim todos os envolvidos sairão vencedores e satisfeitos com o resulto.

\footnotetext{
10 “A resolução colaborativa de conflitos não é uma técnica a ser utilizada exclusivamente por litigantes abastados e somente operada pela advocacia privada. É possível também, com as devidas adaptações, estar à disposição dos órgãos públicos e das classes menos favorecidas economicamente" (Cabral \& Cunha, 2016, p. 09).

${ }^{11}$ Stuart Webb, formou-se em direito e por muitos anos atuou na área de família, onde percebeu e refletiu sobre as dificuldades - quase sempre desnecessárias - da litigância na área do divórcio. Daí resultou a elaboração do direito colaborativo, apresentado em 1990, e desde então trabalha exclusivamente com o seu método, que hoje tem seguidores no mundo todo, além de amplo reconhecimento na mídia internacional. Atualmente está aposentado e leciona nos EUA e na Europa (Webb \& Uousky, 2017).

12 Dra. Tania Almeida (médica), e duas advogadas, Dras. Fernanda Paiva e Flávia Soeiro (Furst, 2013).
} 
A postura da nova advocacia ou então dos advogados colaborativos requer algumas mudanças. O primeiro ponto diz respeito a aproximação com o cliente, sendo é preciso uma escuta empática e humanizada, aliar todo conhecimento jurídico a emoção ${ }^{13}$, para acolher o cliente da melhor forma possível, segundo Cameron (2019), deixar a armadura de distanciamento para com o cliente de lado.

Quando acordam em adotar o procedimento de advocacia colaborativa, as partes convencionam que devem contribuir de maneira construtiva em busca da solução, sem omitir informações solicitadas, sem ameaçar a contraparte com um processo judicial, desta forma todos os envolvidos olham para o conflito com bons olhos, buscando a melhor solução para o conflito (Cabral \& Cunha, 2016).

O procedimento é caracterizado pela racionalidade, que faz com que os envolvidos não exponham sentimentos e emoções ${ }^{14}$, não sendo possível discutir quem errou, buscando apenas soluções eficazes o futuro das partes. Além disso os profissionais não têm permissão de barganha, deve-se fazer uma proposta e aguardar a aceitação ou não da parte contraria, visando total transparência entre todos (Maziero, 2018).

Acredita-se que a advocacia colaborativa possa ser considerada um procedimento fraterno de tratar conflitos, pois todo o processo se dá com base na boa-fé e no diálogo entre os envolvidos, assim, um visualiza o outro, não mais como inimigo e sim como um cidadão detentor de direitos. Assim retiram as roupagens beligerante e combativa e adotam uma postura fraterna para com o próximo.

A advocacia colaborativa é uma forma recente de resolver conflitos e está no Brasil há cerca de uma década. A prática permite que as partes, auxiliadas por seus advogados, por meio de um olhar fraterno para com o próximo, encontrem uma solução criativa para o conflito. Para que os mecanismos cooperativos/colaborativos ganhem ênfase no cenário jurídico brasileiro é preciso educar para a desjudicialização, adotando um ensino mais humano nos cursos de direito, tema abordado no próximo item da pesquisa.

\section{A INCLUSÃO DE FORMAS CONSENSUAIS DE COMPOSIÇÃO DE CONFLITOS NO ENSINO JURÍDICO: POR UMA FORMAÇÃO JURÍDICA MAIS HUMANA}

Há um exaurimento do Poder Judiciário no Brasil que vem se perpetrando ao longo do tempo. Contribui para isso a formação de profissionais para o combate (vencer $x$ perder ${ }^{15}$ ) enquanto poderiam operar para que todos os envolvidos em certo conflito saíssem vitoriosos. Pretende-se aqui realizar um exame quanto a importância de educar profissionais para procedimentos desjudicializadores, bem como estudar a resolução 05/2018 do Ministério da Educação, que regulamenta as diretrizes dos currículos dos cursos de direito no País.

Numerosas demandas sociais estão por se tornar jurídicas, visto que a norma determina o cumprimento, mas o Estado não garante, o que gera "explosão de litigiosidade" ${ }^{16}$. Assim quando se

\footnotetext{
13 “Não estou sugerindo que o intelecto não é necessário para essa advocacia; estou sugerindo que o intelecto seja moldado por um coração aberto" (Cameron, 2019, p. 159).

${ }^{14}$ Neste ponto é relevante destacar a diferença do procedimento de advocacia colaborativa para a mediação, visto que na mediação as partes trazem a tona sentimentos e emoções.

15 “No que tange à justiça, esta acaba, por vezes, sendo vista como mais uma arena de rivalidade, [...] em que o cidadão busca pelo veredito do juiz a glorificação do vencedor, em detrimento do vencido. Mas, se por um lado os profissionais responsáveis pelo exercício da ciência que se destina a empregar as normas jurídicas vigentes, podem desenvolver-se em perspicazes hábitos de disputa, por outro lado, podem, de igual maneira, receber uma preparação acurada acerca dos benefícios da justiça consensual, no decorrer dos anos que perdura o curso" (Stangherlin \& Spengler, 2018, p. 132). ${ }^{16}$ É comprovada a morosidade do Poder Judiciário, através do relatório elaborado anualmente pelo Conselho Nacional de Justiça (CNJ), chamado de Justiça em Números, que apontou uma taxa de congestionamento de $73 \%$ (incluindo os processos de execução, suspensos, sobrestados e em arquivo provisório), ficando a taxa líquida de congestionamento em sede de 1 o grau em 69,1\% (CNJ, 2021).
} 
fala em crise do Estado, este tema está intrinsecamente ligado à crise da Justiça e do próprio direito" (Morais; Spengler, 2019, p. 79). Barroso (2021) ressalta, ainda, que é importante que o Judiciário esteja disponível para resolver conflitos, é positivo. Entretanto, sobressai um lado negativo, no que diz respeito à judicialização de questões políticas, pois, se todas as demandas sociais vêm sendo judicializadas, significa que não estão sendo tratadas nos órgãos em que deveriam fazê-lo ${ }^{17}$. Ou seja, a situação dá ênfase ao mau funcionamento dos órgãos eletivos coordenados pelos Poderes Legislativo e Judiciário.

O conflito algo natural e inerente ao ser humano, apesar de remeter à ideia negativa, ele não é algo necessariamente ruim. Do contrário, há entendimento no sentido de que o conflito possui aspectos positivos, visto que "Uma sociedade sem conflitos é estática" (Morais \& Spengler, 2019, p. 47).

O conflito é uma forma social possibilitadora de elaborações evolutivas e retroativas no concernente a instituições, estruturas e interações sociais, possuindo capacidade de constituirse num espaço em que o próprio confronto é um ato de reconhecimento, produzindo simultaneamente, uma transformação nas relações daí resultantes. Desse modo o conflito pode ser classificado como um processo dinâmico de interação humana e confronto de poder no qual uma parte influência e qualifica o movimento da outra (Morais \& Spengler, 2019, p. 47-48).

É salutar que os atores do direito se debrucem na busca de práticas e técnicas processuais que sirvam além da legislação, que cumpram determinada função social. É preciso educar a população e juristas para que saibam que o acesso à justiça, vai muito além dos Tribunais (Capelletti \& Garth, 1988).

A educação precisa ser diferente do ensino, ela ajuda a tornar os cidadãos mais humanos, a aprender a viver. Seres humanos são complexos e o conflito é essencial para a evolução das pessoas (Warat, 2004). Para desenvolver uma formação adequada é preciso que as universidades se tornem um berço de amplos debates e discussões sobre os mais diversos temas (Araujo et. al., 2020).

Tão logo a importância dos conflitos para a evolução da sociedade, é necessário que sejam desenvolvidas formas de resolvê-los sem acionar o Poder Judiciário. Nesse sentido surgiram as medidas colaborativas, que nem sempre são postas em prática com afinco por operadores do direito, por esse motivo é necessário que se eduque para desjudicialização.

O Ministério da Educação promulgou em 2018 a Resolução de no 5, que prevê no artigo 3o a inclusão de formas consensuais de composição de conflito nos currículos do curso de direito.

Art. 3ํ curso de graduação em Direito deverá assegurar, no perfil do graduando, sólida formação geral, humanística, capacidade de análise, domínio de conceitos e da terminologia jurídica, capacidade de argumentação, interpretação e valorização dos fenômenos jurídicos e sociais, além do domínio das formas consensuais de composição de conflitos, aliado a uma postura reflexiva e de visão crítica que fomente a capacidade e a aptidão para a aprendizagem, autônoma e dinâmica, indispensável ao exercício do Direito, prestação da justiça e ao desenvolvimento da cidadania (Brasil, 2018).

O prazo para que as instituições de ensino se adequassem a norma era de dois anos a partir da data da publicação, entretanto devido a pandemia COVID-19 que assolou o mundo todo, houve a prorrogação pelo período de mais um ano, sendo obrigatório a inclusão até dezembro de 2021. Tal mudança na matriz curricular permite a formação de profissionais mais humanos, que atuarão sempre buscando a pacificação social.

\footnotetext{
17 “O que verifica, então, é a desconexão entre o aparelho judicial e o sistema político e social, distanciando-se a lei (e, por conseguinte, sua interpretação e sua aplicação) da sociedade na qual se encontra inserida, não correspondendo, assim, à expectativa de tratamento adequado aos conflitos." (Spengler, 2007, p. 151).
} 
É essencial/necessário educar para os direitos humanos, principalmente no que diz respeito ao acesso à justiça que respalda e busca prevenir/garantir determinado direito (Capelletti; Garth, 1988). Mister reforçar que nenhuma reforma nas matrizes curriculares pretende substituir a necessidade de reformas sociais e políticas no país, mas a educação assume um importante papel no que tange a efetivação do acesso à justiça (Stangherlin \& Spengler, 2018).

Os Direitos Humanos, suas lutas, suas conquistas utópicas, ainda que mostrem muitas vezes sua proximidade com o impossível, ainda que tenha sempre uma ressonância de um sonho quase impossível, mostram ao longo da história que essa quase impossibilidade se torna, por momentos, possível. Os Direitos Humanos representam e encarnam historicamente a esperança que impulsiona a ação de muitos movimentos que ainda têm fé e apostam em que esse impossível, que é cada vez mais urgente, se faz possível (Warat, 2004, p. 148-149).

Acredita-se ser primordial que se eduque os acadêmicos de direito para que se tornem profissionais cooperativos. Sendo juristas capacitados para buscar sempre o melhor para o cliente, sem esquecer da função social desta prestação, que vise o bem estar coletivo da sociedade.

Destaca-se que apesar das legislações que fomentam os procedimentos cooperativos/colaborativos o número de demandas ingressadas junto ao Poder Judiciário é considerado altíssimo, sendo no ano de 2020 o total de 25,9 milhões de processos (CNJ, 2021), sendo salutar que os operadores do direito tenham consciência de sua responsabilidade neste fenômeno.

Diante do exposto é notório que mudanças estão sendo pensadas pelos órgãos responsáveis por regulamentar o ensino jurídico no país, como denota-se da Resolução no 5/2018. Acredita-se que formando profissionais colaborativos, com inspirações voltadas para a humanização do direito, os resultados serão sentidos em todas as esferas sociais. Por hora, se faz necessário aguardar o prazo para final para que todas as faculdades de direito se adequem a normativa do Ministério da Educação e avaliar os resultados desta mudança na atuação dos operadores do direito.

\section{CONCLUSÃO}

A presente pesquisa teve como foco estudar a importância de uma educação humanizada no ensino jurídico brasileiro, propondo a inclusão de práticas cooperativas na matriz curricular dos cursos de direito, sendo que o método adotado foi eficaz para concluir a pesquisa.

Para tanto foi feito um estudo da criação e da evolução dos cursos de direito no país, desde uma formação elitista até os dias atuais, na busca de uma formação mais humanizada, com pano de fundo social. Foram abordados os procedimentos de mediação e de advocacia colaborativa, enquanto mecanismos fomentadores da pacificação social, que devem ser adotados pelos operadores do direito, visando a retomada do diálogo pelos conflitantes e a pacificação social.

Por fim, foi estudada a Resolução no 5/2018 que determina a inclusão de formas consensuais de composição de conflito nos currículos do curso de direito, que deve ser implementada por todas as instituições de ensino até dezembro de 2021.

Conclui-se que é salutar incluir nas grades curriculares do ensino jurídico práticas colaborativas, visando a formação de profissionais, menos litigantes, mais pacificadores e humanos. Formar profissionais desjudicializadores é essencial para garantir uma sociedade livre, justa, solidária e fraterna, como preceitua a Constituição Federal.

Contribuições dos Autores: Spengler, F. M.: concepção e desenho, aquisição de dados, análise e interpretação dos dados, redação do artigo, revisão crítica relevante do conteúdo intelectual; Dornelles, M.: concepção e desenho, aquisição de dados, análise e interpretação dos dados, redação do artigo, revisão crítica relevante do conteúdo intelectual. As autoras leram e aprovaram a versão final do manuscrito. 
Aprovação Ética: Não aplicável.

Agradecimentos: Não aplicável.

\section{REFERÊNCIAS}

Araújo, R. G. de, Francisco, M. V., \& Noguchi, C. de S. (2020). O O processo formativo de estudantes de direito diante da temática violência contra as mulheres. Revista Tempos e Espaços em Educação, 13(32), 1-22.

https://doi.org/10.20952/revtee.v13i32.13288

Barroso, L. R. (2021). A judicialização da vida e o papel do Supremo Tribunal Federal. Belo Horizonte: Fórum.

Bissoli Filho, F. (2020). Das reformas dos cursos de Direito às reformas do ensino jurídico no Brasil: a importância dos professores e alunos na discussão das reformas e no processo ensino-aprendizagem. In: Rodrigues, H. W., \& Arruda Junior, E. L. (Org.). Educação Jurídica. Florianopolis, Editora Fundação Boiteux, 09-50.

Brasil. [Constituição (1988)]. Constituição da República Federativa do Brasil. Brasília, DF: Senado Federal.

Brasil. (2015). Lei n. 13.105, de 16 de março de 2015. Brasília: Presidência da República, 2015a. Disponível em: http://www.planalto.gov.br/ccivil 03/ ato2015-2018/2015/lei//13105.htm

Brasil (2015). Lei n. 13.140, de 26 de junho de 2015. Brasília: Presidência da República, c. Disponível em: http://www.planalto.gov.br/ccivil 03/ ato20152018/2015/Lei/L13140.htm

Brasil (2010). Resolução n. 125, de 29 de novembro de 2010. Brasília: Conselho Nacional de Justiça, 2010. Disponível em: https://atos.cnj.jus.br/atos/ detalhar/atos-normativos?documento=156

Brasil (2016). Resolução n. 174, de 30 de setembro de 2016. Brasília: Conselho Superior da Justiça do Trabalho, 2016. Disponível em: http://www.csjt.jus.br/c/document library/get file?uuid=235e3400-9476-47a0-8bbbbccacf94fab4\&groupld $=955023$

Brigagão, C. G. (2020). A história do ensino do direito no Brasil e o movimento de suas diretrizes curriculares nacionais. In: Rocha, M. V., \& Barroso, F. R. (Org.). Educação jurídica e didática no ensino do direito. Florianópolis, Habitus. 43-64.

Cameron, N. J. (2019). Práticas colaborativas: aprofundando o diálogo. São Paulo: Instituto Brasileiro de Práticas colaborativas.

Cappelletti, M., \& Garth, B. (1988). Acesso à justiça. Porto Alegre: Sérgio Antonio Fabris.

Conselho Nacional de Justiça. (2020). Justiça em números. Brasília: CNJ, 2021. Disponível em:

https://www.cnj.jus.br/pesquisas-judiciarias/justica-em-numeros/

Cabral, T. N. X. (2017). A evolução da conciliação e da medicação no brasil. Revista FONAMEC, 1(1), 354-369.

Calmon, P. (2013). Fundamentos da mediação e da conciliação. Brasília: Gazeta Jurídica.

Cunha, L. C., \& Cabral, A. (2016). Negociação direta ou resolução colaborativa de disputas (collaborative law): mediação sem mediador. Revista de Processo, 471-489.

Furst, O. (2010). Premio Innovare. Advocacia colaborativa, mediação de conflitos. Disponível em: https://www.oliviafurst.adv.br/premio-innovare2

Gomes, M. S. M. (2019). Práticas colaborativas: uma alternativa de não litigância. (Re)pensando Direito, 9(18), 80-92.

Maciel, L. S. B. \& Shigunov Neto, A. (2006). A educação brasileira no período pombalino: uma análise histórica das reformas pombalinas do ensino. Revista Educação e Pesquisa, 32(3), 465-476. https://doi.org/10.1590/S151797022006000300003

Ministério da Educação. Resolução no 05/ 2018. Institui sobre as diretrizes curriculares do curso de direito. Disponível em: http://portal.mec.gov.br/index.php?option=com docman\&view=download\&alias=104111-rces005-

18\&category slug=dezembro-2018-pdf\&Itemid=30192

Morais, J. L. B.; Spengler, F. M. (2019). Mediação e arbitragem: alternativa à jurisdição! 4. ed. rev. e atual. Porto Alegre: Livraria do Advogado.

Martinez, S. (2005). Evolução do Ensino Jurídico no Brasil. Disponível em:

https://pt.scribd.com/document/109530832/Evolucao-do-Ensino-Juridico-no-Brasil-Sergio-Martinez

Maziero, F. G. M. (2018). Inovação na solução de conflitos: a advocacia colaborativa. Revista Percurso Acadêmico, 8(15), 23-46. https://doi.org/10.5752/P.2236-0603.2018v8n15p23-46 
Schaefer, R. P., Spengler, F. M. (2019). O papel social das universidades comunitárias enquanto terceiro no tratamento dos conflitos. Revista Direito e Paz, 41(2), 91-107. https://doi.org/10.32713/rdp.v2i41.1140

Souza, J. S., Santos, C. P. (2018). Advocacia Colaborativa. OAB - SERGIPE. [RECURSO ELETRÓNICO]. Disponível em: http://oabsergipe.org.br/wp-content/uploads/2018/10/ADVOCACIA-COLABORATIVA.pdf

Spengler, F. M. (2021). Mediação de Conflitos: da teoria à prática. Porto Alegre: Livraria do Advogado.

Spengler, F. M. (2007). O Estado-jurisdição em crise e a instituição do consenso: por uma outra cultura no tratamento de conflitos. 2007. Tese (Doutorado em Direito) - Escola de Direito, Programa de Pós-Graduação em Direito, Universidade do Vale do Rio dos Sinos, São Leopoldo, SP.

Stangherlin, C. S., \& Spengler, F. M. (2018). A atual formação acadêmica dos profissionais de direito e a justiça consensual: Um estudo acerca das matrizes curriculares dos cursos de direito das universidades comunitárias do Rio Grande do Sul-Brasil. Revista Eletrônica do Centro Universitário Rio São Francisco, 19, 127-142. Disponível em: https://www.unirios.edu.br/revistarios/internas/conteudo/resumo.php?id=374

Warat, L. A. (2004). Surfando na pororoca: o ofício do mediador. Florianópolis: Fundação Boiteux.

Webb, S. G., \& Ousky, R. D. (2018). O caminho colaborativo do divórcio. Rio de Janeiro: Instituto Brasileiro de Práticas colaborativas.

Recebido: 30 de novembro de 2020 | Aceito: 15 de outubro de 2021 | Publicado: 17 de novembro de 2021 